\title{
Gambaran Ketersediaan Sumber Daya Manusia dan Prasarana Puskesmas dalam Pelaksanaan Program Indonesia Sehat dengan Pendekatan Keluarga (PIS-PK): Analisis Data Risnakes 2017
}

\author{
Availability of the Human Resources (HR) and Primary Health Care's \\ Infrastructure in the Implementation of Program Indonesia Sehat dengan \\ Pendekatan Keluarga (PIS-PK): Data Analysis of Risnakes 2017
}

Sugiharti $^{1}$, Mujiati ${ }^{2}$, Siti Masitoh ${ }^{1}$, dan Eva Laelasari ${ }^{1}$

1) Pusat Penelitian dan Pengembangan Upaya Kesehatan Masyarakat, Jalan Percetakan Negara No. 29 Jakarta 10560 , Indonesia

2) Pusat Penelitian dan Pengembangan Sumber Daya dan Pelayanan Kesehatan, Jalan Percetakan Negara No. 29 Jakarta 10560, Indonesia

Korespondensi:sg_atik@yahoo.co.id

Submitted: 15 Februari 2019, Revised: 15 April 2019, Accepted: 22April 2019

https://doi.org/10.22435/jpppk.v3i1.1883

\begin{abstract}
Abstrak
Program Indonesia Sehat merupakan program utama Pembangunan Kesehatan yang direncanakan pencapaiannya melalui Rencana Strategis Kementerian Kesehatan Tahun 2015-2019. Program Indonesia Sehat dengan Pendekatan Keluarga (PIS-PK) menjadi salah satu cara puskesmas untuk meningkatkan jangkauan sasaran dan mendekatkan/meningkatkan akses pelayanan kesehatan di wilayah kerjanya dengan mendatangi keluarga. Untuk mendukung pelaksanaan pendekatan keluarga tersebut perlu adanya penguatan puskesmas sebagai salah satu ujung tombaknya. Penguatan tersebut antara lain dilakukan melalui pemenuhan sumber daya puskesmas, yakni sumber daya manusia (SDM), prasarana dan sarana/alat. Tujuan dari analisis ini adalah mengetahui ketersediaan SDM dan prasarana-sarana puskesmas dalam menjalankan PIS-PK. Hasil analisis ini menunjukkan bahwa tenaga pendukung kegiatan pengumpulan data PIS-PK di puskesmas seluruh Indonesia yang mengikuti pelatihan PIS-PK paling banyak adalah tenaga bidan (29,8\%), sedangkan petugas yang paling banyak melakukan pengumpulan data keluarga sehat adalah petugas puskesmas (94,5\%). Prasarana yang mendukung kegiatan PIS-PK di puskesmas menunjukkan bahwa hampir semua puskesmas dalam melakukan pendataan menggunakan formulir Prokesga sebanyak 97,8 persen. Keberadaan sinyal telepon selular di puskesmas sebanyak 85,5 persen dan keberadaan sinyal internet sebanyak 73,2 persen. Baru separuh puskesmas memiliki Pinkesga sebanyak 58,5 persen, stetoskop dan alat ukur tekanan darah air raksa, hampir semua puskesmas memiliki alat tersebut. Alat ukur tekanan darah digital hanya 71,4 persen.
\end{abstract}

Kata kunci: PIS-PK, Keluarga Sehat, Puskesmas

\section{Abstract}

The Healthy Indonesia Program (Program Indonesia Sehat) is the main health development program planned to achieve through the Ministry of Health's Strategic Plan for 2015-2019. Program Indonesia Sehat dengan Pendekatan Keluarga (PIS-PK) is one of the ways the primary health care (PHC) can increase the reach of targets and bring closer / increase access to health services in their working areas by visiting families. To support the implementation of the family approach it is necessary to strengthen the PHC's as one of the spearheads. Such reinforcement, among others, is done through the fulfillment of PHC's resources, including human resources, infrastructure and tools. The purpose of this study is to find out about the readiness of Human Resources and Infrastructure Facilities of PHC in running PIS-PK. The results of this study indicate 
that for workers who support the PIS-PK data collection activities in health centers throughout Indonesia, the highest number of midwives is 29.8 percent who attend the PIS-PK training and the most 94.5 percent. Whereas for infrastructure that supports PIS-PK activities at the PHC, it shows that almost all PHC in carrying out the data collection used the Prokesga form as much as 97.8 percent. The presence of mobile cellular signals in PHC is 85.5 percent and the presence of internet signals is 73.2 percent. Whereas for the availability of Pinkesga, only half of the PHC have Pinkesga as much as 58.5 percent, while for stethoscopes and mercury blood pressure measuring devices, almost all PHC have these devices, for digital blood pressure measuring devices only 71.4 percent

\section{Keywords: PIS-PK, Health Family, primary health care (PHC)}

\section{Pendahuluan}

Salah satu Program Indonesia Sehat, yang merupakan agenda ke-5 Nawa Cita, adalah meningkatkan kualitas hidup manusia Indonesia. Program Indonesia Sehat selanjutnya menjadi program utama pembangunan kesehatan, yang kemudian direncanakan pencapaiannya melalui Rencana Strategis (Renstra) Kementerian Kesehatan Tahun 2015-2019. Program Indonesia Sehat (PIS) dilaksanakan untuk meningkatkan derajat kesehatan masyarakat melalui upaya kesehatan dan pemberdayaan masyarakat yang didukung dengan pelindungan finansial dan pemerataan pelayanan. ${ }^{1}$

Sasaran ini sesuai dengan sasaran pokok RPJMN 2015-2019, yaitu: (1) meningkatnya status kesehatan dan gizi ibu dan anak, (2) meningkatnya pengendalian penyakit, (3) meningkatnya akses dan mutu pelayanan kesehatan dasar dan rujukan terutama di daerah terpencil, tertinggal dan perbatasan, (4) meningkatnya cakupan pelayanan kesehatan universal melalui Kartu Indonesia Sehat dan kualitas pengelolaan SJSN kesehatan, (5) terpenuhinya kebutuhan tenaga kesehatan, obat dan vaksin, serta (6) meningkatnya responsivitas sistem kesehatan. $^{2}$

Program Indonesia Sehat dengan Pendekatan Keluarga (PIS-PK) mengintegrasikan pelaksanaan program melalui pendekatan 6 komponen utama dalam penguatan sistem kesehatan (six building blocks), yaitu penguatan upaya pelayanan kesehatan, ketersediaan tenaga kesehatan, sistem informasi kesehatan, akses terhadap ketersediaan obat esensial, pembiayaan, dan kepemimpinan atau pemerintahan. Pelaksanaan PIS-PK ditekankan pada integrasi pendekatan akses pelayanan kesehatan, ketersediaan tenaga kesehatan, pembiayaan dan prasarana-sarana, termasuk program upaya kesehatan masyarakat dan perseorangan yang mencakup seluruh keluarga dalam wilayah kerja puskesmas dan memperhatikan manajemen puskesmas. ${ }^{3}$

Upaya pencapaian prioritas pembangunan kesehatantahun 2015-2019 dalam Program Indonesia Sehat dilaksanakan dengan mendayagunakan segenap potensi yang ada baik dari pemerintah pusat, provinsi, kabupaten/kota, maupun masyarakat. Pembangunan kesehatan dimulai dari unit terkecil dari masyarakat, yaitu keluarga. Program Indonesia Sehat dengan Pendekatan Keluarga (PIS-PK) menjadi salah satu cara puskesmas untuk meningkatkan jangkauan sasaran dan mendekatkan/ meningkatkan akses pelayanan kesehatan diwilayah kerjanya dengan mendatangi keluarga. Puskesmas tidak hanya menyelenggarakan pelayanan kesehatan di dalam gedung, melainkan juga keluar gedung dengan mengunjungi keluarga-keluarga di wilayah kerjanya. Kunjungan rumah (keluarga) dilakukan secara terjadwal dan rutin, dengan memanfaatkan data dan informasi dari Profil Kesehatan Keluarga (Prokesga). ${ }^{4}$

PIS-PK telah dilaksanakan mulai tahun 2016 di 9 Provinsi di 64 kabupaten/kota dari 9 provinsi pada 470 puskesmas prioritas yang jumlah kematian ibu dan bayi baru lahirnya masih tinggi. Kemudian pada tahun 2017 dilaksanakan di 514 kabupaten/ kota dari 34 Provinsi pada 2.926 puskesmas, 5.852 puskesmas di tahun 2018, dan pada tahun 2019 dilaksanakan di seluruh puskesmas. ${ }^{5}$

Pusat Kesehatan Masyarakat yang selanjutnya disebut puskesmas, adalah fasilitas pelayanan kesehatan yang menyelenggarakan upaya kesehatan masyarakat dan upaya kesehatan perseorangan tingkat pertama, dengan lebih mengutamakan upaya promotif dan preventif, untuk mencapai derajat kesehatan masyarakat yang setinggi-tingginya di wilayah kerjanya. ${ }^{6}$ Kementerian Kesehatan RI berupaya meningkatkan 
fungsi puskesmas sebagai garda terdepan layanan kesehatan di masyarakat. Langkah itu dilakukan dengan berupaya memenuhi prasarana serta fasilitas kesehatan agar memadai. Salah satunya dengan pemerataan alat kesehatan bagi puskesmas. ${ }^{7}$

Peraturan Menteri Kesehatan Nomor 75 Tahun 2014 menyatakan bahwa salah satu prinsip penyelenggaraan puskesmas adalah pemerataan dalam penyelenggaraan pelayanan puskesmas harus dapat diakses dan terjangkau oleh seluruh masyarakat di wilayah kerjanya. ${ }^{6}$ Untuk mendukung pelaksanaan pendekatan keluarga tersebut perlu ada penguatan puskesmas sebagai salah satu ujung tombaknya. Penguatan tersebut antara lain dilakukan melalui pemenuhan sumber daya puskesmas antara lain sumber daya manusia (SDM), prasarana dan sarana/alat. Dari 2.926 puskesmas yang menjadi target pendekatan keluarga tahun 2017 hanya terdapat 38 persen puskesmas yang prasarananya sesuai dengan standar. Sebagai konsekuensinya perlu dilakukan berbagai intervensi agar target pemenuhan standar Sarana, Prasarana dan Alat Kesehatan (SPA) di puskesmas tersebut sesuai standar.

Artikel ini merupakan bagian dari hasil Riset Ketenagaan di Bidang Kesehatan (Risnakes) Tahun 2017. Tujuan penelitian ini adalah mengetahui ketersediaan SDM dan SPA di puskesmas dalam menjalankan PIS-PK. Ketersediaan SDM dan SPA puskesmas ini penting dilakukan, karena untuk menilai kesiapan puskesmas dalam pelaksanaan PIS-PK. Pelaksanaan PIS-PK ditekankan pada integrasi pendekatan akses pelayanan kesehatan, adanya ketersediaan tenaga kesehatan, pembiayaan dan prasarana, termasuk upaya program kesehatan masyarakat dan perseorangan yang mencakup seluruh keluarga dalam wilayah kerja puskesmas dengan memperhatikan manajemen puskesmas. ${ }^{3}$

\section{Metode}

Riset Ketenagaan di Bidang Kesehatan (Risnakes) dilakukan pada tahun 2017. Penelitian ini dilakukan di seluruh puskesmas di Indonesia yang berjumlah 9.699 puskesmas. Desain penelitian adalah potong lintang (cross sectional) dengan metode sensus. Pengumpulan data dilakukan melalui wawancara terhadap Kepala Puskesmas atau Kepala Bagian Tata Usaha atau Penanggung
Jawab Keluarga Sehat (PJ KS) atau petugas puskesmas yang dianggap mengerti tentang PISPK. Data yang dikumpulkan berupa data kuantitatif dan data dianalisis secara deskriptif. Prasarana yang digunakan untuk menilai kesiapan puskesmas dalam menjalankan PIS-PK adalah peralatan yang digunakan untuk melakukan pendataan. Adapun peralatan yang didata dalam artikel ini adalah formulir Prokesga, Pinkesga, stetoskop, alat ukur tekanan darah air raksa, dan alat ukur tekanan darah digital.

\section{Hasil}

Pelaksanaan Program Indonesia Sehat dengan Pendekatan Keluarga (PIS-PK) ditekankan pada integrasi pendekatan akses pelayanan kesehatan, ketersediaan tenaga kesehatan, pembiayaan dan prasarana, termasuk program upaya kesehatan masyarakat dan perseorangan yang mencakup seluruh keluarga dalam wilayah kerja puskesmas dengan memperhatikan manajemen puskesmas. Adapun tahapan pelaksanaan PIS-PK adalah pelaksanaan pelatihan keluarga sehat dalam mendukung PIS-PK; pelaksanaan persiapan PISPK; pelaksanaan kunjungan keluarga dan intervensi awal PIS-PK; pelaksanaan analisis indeks keluarga sehat (IKS) awal; pelaksanaan intervensi lanjut PISPK; pelaksanaan analisis perubahan IKS. ${ }^{3}$

\section{Sumber Daya Manusia}

Tabel 1 menunjukkan jumlah puskesmas yang sudah dilatih keluarga sehat. Terdapat 3.696 puskesmas yang sudah dilatih PIS-PK dan 6.001 puskesmas yang belum dilatih PIS-PK. Puskesmas sudah dilatih PIS PK yaitu puskesmas yang sudah mengikuti pelatihan PIS-PK yang diselenggarakan oleh Bapelkes nasional, provinsi ataupun daerah pada tahun 2016 ke atas.

Grafik 1 menggambarkan persentase jenis petugas yang mengikuti pelatihan keluarga sehat. Dari Grafik 1 ini terlihat bahwa bidan $(29,8 \%)$ dan perawat $(26,2 \%)$ adalah jenis tenaga yang paling banyak mengikuti pelatihan keluarga sehat. Jenis petugas yang paling sedikit mengikuti pelatihan adalah tenaga farmasi $(1,7 \%)$.

Grafik 2 menggambarkan jenis petugas yang melakukan pengumpulan data keluarga sehat atau melakukan kunjungan keluarga. Terlihat 
Tabel 1. Persentase Puskesmas yang Dilatih PIS PK dan yang Belum Dilatih PIS PK Berdasarkan Provinsi, Risnakes 2017

\begin{tabular}{|c|c|c|c|c|c|c|}
\hline \multirow[t]{2}{*}{ No. } & \multirow[t]{2}{*}{ Nama Provinsi } & \multirow[t]{2}{*}{$\begin{array}{l}\text { Jumlah } \\
\text { Puskesmas }\end{array}$} & \multicolumn{2}{|c|}{$\begin{array}{c}\text { Puskesmas Dilatih } \\
\text { PIS PK }\end{array}$} & \multicolumn{2}{|c|}{$\begin{array}{c}\text { Puskesmas Belum Dilatih } \\
\text { PIS PK }\end{array}$} \\
\hline & & & $\mathrm{n}$ & $\%$ & $\mathrm{n}$ & $\%$ \\
\hline 1 & Aceh & 340 & 195 & 57,4 & 145 & 42,6 \\
\hline 2 & Sumatra Utara & 571 & 292 & 51,1 & 279 & 48,9 \\
\hline 3 & Sumatra Barat & 264 & 109 & 41,3 & 155 & 58,7 \\
\hline 4 & Riau & 212 & 88 & 41,5 & 124 & 58,5 \\
\hline 5 & Jambi & 176 & 79 & 44,9 & 97 & 55,1 \\
\hline 6 & Sumatra Selatan & 322 & 128 & 39,8 & 194 & 60,2 \\
\hline 7 & Bengkulu & 179 & 51 & 28,5 & 128 & 71,5 \\
\hline 8 & Lampung & 291 & 210 & 72,2 & 81 & 27,8 \\
\hline 9 & Kepulauan Bangka Belitung & 62 & 26 & 41,9 & 36 & 58,1 \\
\hline 10 & Kepulauan Riau & 72 & 48 & 66,7 & 24 & 33,3 \\
\hline 11 & DKI Jakarta & 314 & 93 & 29,6 & 221 & 70,4 \\
\hline 12 & Jawa Barat & 1050 & 352 & 33,5 & 698 & 66,5 \\
\hline 13 & Jawa Tengah & 875 & 474 & 54,2 & 401 & 45,8 \\
\hline 14 & DI Yogyakarta & 121 & 35 & 28,9 & 86 & 71,1 \\
\hline 15 & Jawa Timur & 960 & 481 & 50,1 & 479 & 49,9 \\
\hline 16 & Banten & 233 & 97 & 41,6 & 136 & 58,4 \\
\hline 17 & Bali & 120 & 50 & 41,7 & 70 & 58,3 \\
\hline 18 & Nusa Tenggara Barat & 158 & 95 & 60,1 & 63 & 39,9 \\
\hline 19 & Nusa Tenggara Timur & 371 & 42 & 11,3 & 329 & 88,7 \\
\hline 20 & Kalimantan Barat & 238 & 61 & 25,6 & 177 & 74,4 \\
\hline 21 & Kalimantan Tengah & 195 & 29 & 14,9 & 166 & 85,1 \\
\hline 22 & Kalimantan Selatan & 230 & 81 & 35,2 & 149 & 64,8 \\
\hline 23 & Kalimantan Timur & 173 & 53 & 30,6 & 120 & 69,4 \\
\hline 24 & Kalimantan Utara & 46 & 15 & 32,6 & 31 & 67,4 \\
\hline 25 & Sulawesi Utara & 185 & 48 & 25,9 & 137 & 74,1 \\
\hline 26 & Sulawesi Tengah & 189 & 80 & 42,3 & 109 & 57,7 \\
\hline 27 & Sulawesi Selatan & 448 & 204 & 45,5 & 244 & 54,5 \\
\hline 28 & Sulawesi Tenggara & 268 & 42 & 15,7 & 226 & 84,3 \\
\hline 29 & Gorontalo & 93 & 24 & 25,8 & 69 & 74,2 \\
\hline 30 & Sulawesi Barat & 94 & 28 & 29,8 & 66 & 70,2 \\
\hline 31 & Maluku & 198 & 24 & 12,1 & 174 & 87,9 \\
\hline 32 & Maluku Utara & 127 & 22 & 17,3 & 105 & 82,7 \\
\hline 33 & Papua Barat & 150 & 20 & 13,3 & 130 & 86,7 \\
\hline 34 & Papua & 372 & 20 & 5,4 & 352 & 94,6 \\
\hline & INDONESIA & 9.697 & 3.696 & 38,1 & 6.001 & 61,9 \\
\hline
\end{tabular}

*Sumber: Laporan Riset Ketenagaan Bidang Kesehatan 2017 
bahwa petugas yang paling banyak melakukan pengumpulan data keluarga sehat adalah petugas puskesmas (94,5\%), kader (53\%), kemudian mahasiswa kesehatan $(9,1 \%)$.

\section{Prasarana Puskesmas}

Grafik 3 menunjukkan ketersediaan instrumen pendataan. Terlihat bahwa hampir semua puskesmas sudah menggunakan formulir Prokesga $(97,8 \%)$ dan hanya 62,3 persen menggunakan Aplikasi Keluarga Sehat.

Grafik 4 menunjukkan keberadaan sinyal telepon seluler (ponsel) di puskesmas yang sudah dilatih PIS-PK adalah sebanyak 85,5 persen, sedangkan untuk keberadaan sinyal internet sebanyak 73,2 persen.

Grafik 5 menggambarkan bahwa ketersediaan prasarana kegiatan pendataan PIS-PK di puskesmas yang sudah dilatih PIS-PK. Terlihat

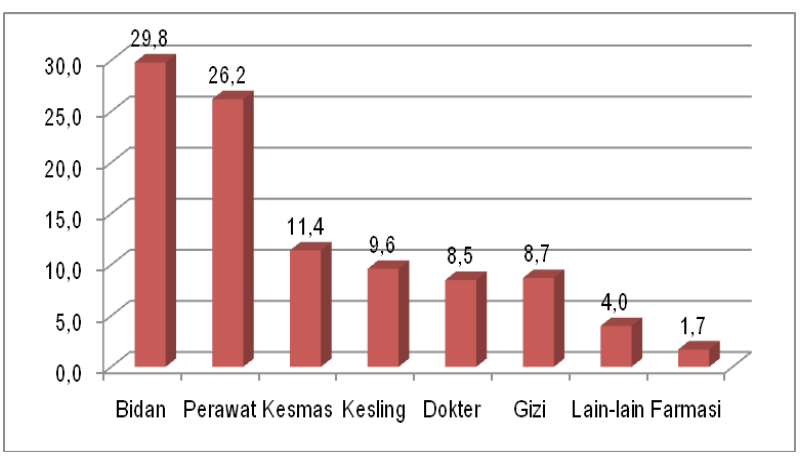

Grafik 1. Persentase Jenis Petugas yang Mengikuti Pelatihan PIS-PK pada Puskesmas Sudah Dilatih, Risnakes 2017

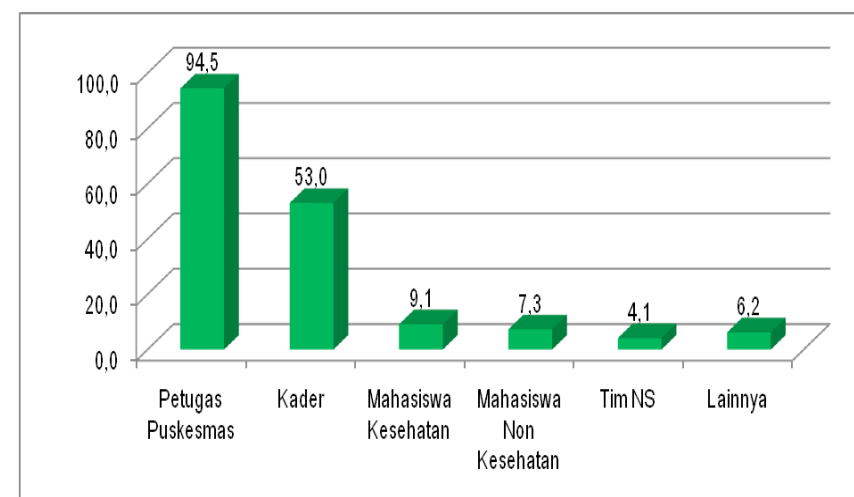

Grafik 2. Persentase Jenis Petugas Pengumpul Data PIS-PK pada Puskesmas Sudah Dilatih PIS-PK, Risnakes 2017

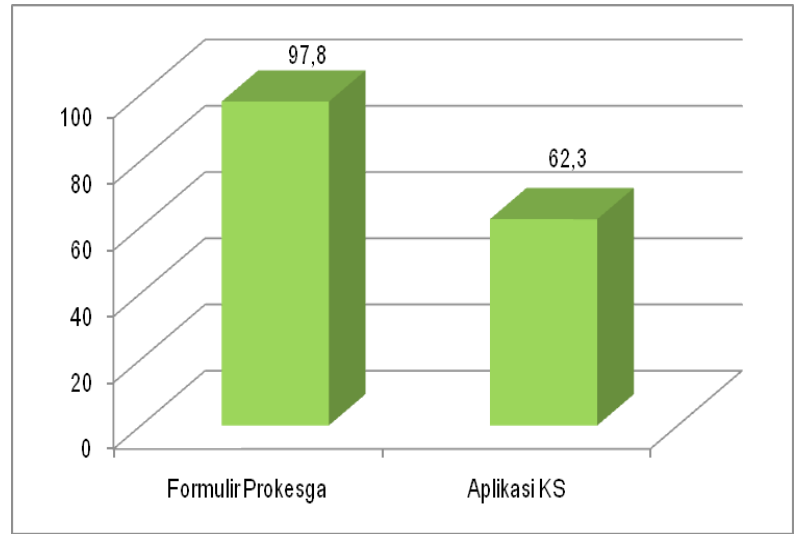

Grafik 3. Persentase Puskesmas Sudah Dilatih PIS-PK menurut Ketersediaan Instrumen Pendataan, Risnakes 2017

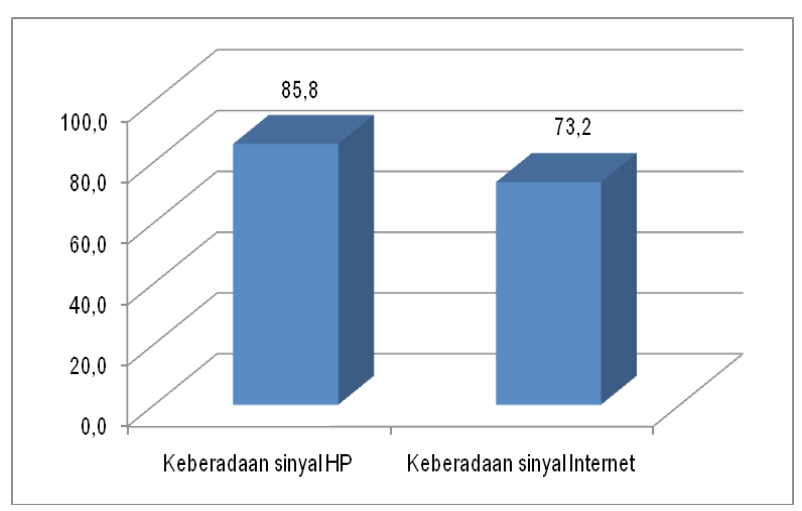

\section{Grafik 4. Persentase Puskesmas menurut Keberadaan Sinyal Telepon Seluler dan Sinyal Internet, Risnakes 2017}

bahwa baru separuh puskesmas (58,5\%) yang memiliki Pinkesga. Hampir semua puskesmas memiliki stetoskop dan alat ukur tekanan darah air raksa. Alat ukur tekanan darah digital baru 71,4 persen puskesmas yang memiliki.

\section{Pembahasan}

Pendekatan keluarga adalah salah satu cara puskesmas untuk meningkatkan jangkauan sasaran dan mendekatkan/meningkatkan akses pelayanan kesehatan di wilayah kerjanya dengan mendatangi keluarga. Puskesmas tidak hanya menyelenggarakan pelayanan kesehatan di dalam gedung, melainkan juga keluar gedung dengan mengunjungi keluarga-keluarga di wilayah kerjanya. Salah satu pelaksanaan pendekatan keluarga oleh puskesmas 


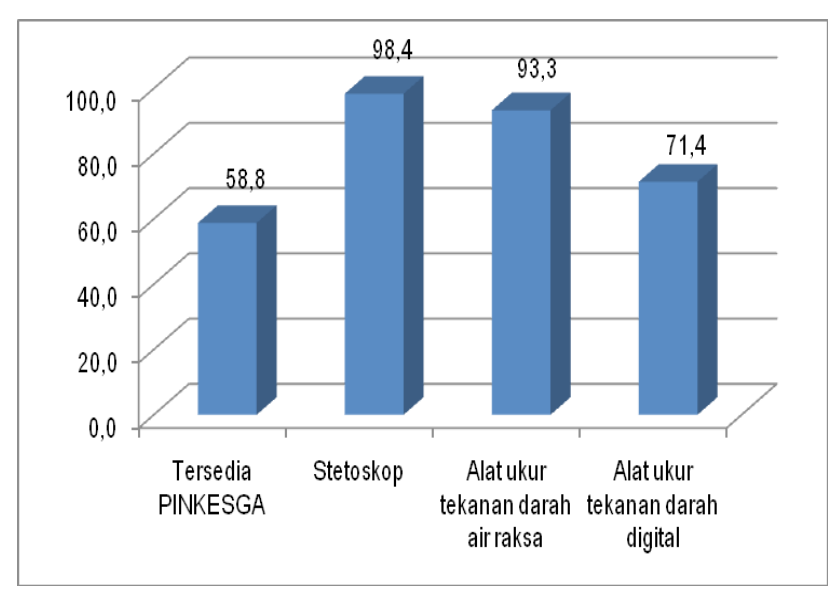

\section{Grafik 5. Persentase Puskesmas menurut Ketersediaan Pinkesga, Stetoskop, Alat Ukur Tekanan Darah Air Raksa, Alat Ukur Tekanan Darah Digital, Risnakes 2017}

adalah melakukan pendataan kesehatan keluarga menggunakan formulir Profil Kesehatan Keluarga (Prokesga). ${ }^{9}$

Sumber daya terpenting dalam rangka pelaksanaan pendekatan keluarga di puskesmas adalah tenaga kesehatan. Walaupun di bidang kesehatan pendekatan keluarga bukan merupakan hal baru, namun sebagian tenaga kesehatan puskesmas yang ada saat ini kurang memahaminya. Sebelum melakukan pendataan, petugas puskesmas dilatih terlebih dulu. Sejak tahun 2017 hingga saat ini sebagian besar puskesmas telah menjadi lokus PIS-PK, dimana lima petugas dari setiap lokus tersebut diberi pelatihan manajemen PIS-PK.

Terdapat 2 puskesmas yang missing dari 9.699 puskesmas yang didata, sehingga jumlah puskesmas yang dianalisis adalah 9.697 puskesmas. Dari 9.697 puskesmas yang di analisis terdapat 3.696 puskesmas yang sudah dilatih PIS-PK. Penelitian ini menggunakan data 3.696 puskesmas yang sudah dilatih PIS-PK.

\section{Sumber Daya Kesehatan}

Grafik 1 memperlihatkan bahwa bidan adalah tenaga kesehatan yang paling banyak mengikuti pelatihan PIS-PK (29,8\%), kemudian diikuti oleh perawat $(26,2 \%)$, dan yang paling sedikit adalah tenaga farmasi $(1,7 \%)$. Hal ini kemungkinan disebabkan jumlah tenaga bidan yang banyak di puskesmas. Sesuai dengan data
Badan PPSDM Kesehatan tahun 2013, sebagian besar Puskesmas kelebihan tenaga bidan, baik di puskesmas perawatan maupun di non-perawatan; di perdesaan dan perkotaan. ${ }^{10}$ Selain bidan memiliki peran sebagai pelaksana dalam pelayanan asuhan kehamilan, persalinan, bayi baru lahir dan Keluarga Berencana (KB), bidan juga berperan pula sebagai pengelola pelayanan dasar kesehatan terutama untuk pelayanan individu, keluarga dan masyarakat. Bidan juga memiliki peran dalam mengelola program kesehatan di wilayah kerjanya. ${ }^{11}$

Tenaga farmasi adalah yang paling sedikit mengikuti pelatihan PIS-PK, kemungkinan disebabkan jumlah tenaga farmasi yang sedikit di puskesmas. Hal tersebut sesuai dengan hasil penelitian Herman, dkk (2013) yang menunjukkan bahwa sebanyak $32,2 \%$ puskesmas tidak memiliki tenaga kefarmasian sama sekali dan 82,5\% puskesmas tidak memiliki apoteker. ${ }^{12}$

Sebagian besar puskesmas menggunakan petugas puskesmas untuk pendataan keluarga sehat dalam melakukan pendataan atau kunjungan ke rumah penduduk sebesar 94,5 persen, sebagian kecil menggunakan tenaga dari tim Nusantara Sehat (NS) 4,1 persen. Hal ini sesuai dengan penelitian Virdasari, dkk (2018) bahwa tenaga pendataan keluarga dilakukan oleh tenaga puskesmas berjumlah 30-50 tenaga medis dan non-medis. ${ }^{13}$ Hal tersebut sesuai juga dengan petunjuk teknis penguatan manajemen puskesmas (2016), bahwa pendataan dilakukan oleh petugas puskesmas dan perekrutan petugas pendataan dilakukan apabila hasil dari analisis kebutuhan tenaga menyatakan bahwa membutuhkan tenaga tambahan berdasarkan pada analisis kebutuhan tenaga pendataan dengan mempertimbangkan aspek ketersediaan tenaga di puskesmas, jumlah keluarga di wilayah kerja puskesmas, luas wilayah kerja, kondisi geografis wilayah kerja, dan pendanaan. Perekrutan petugas pendataan dapat dilaksanakan apabila hasil dari analisis kebutuhan tenaga menyatakan bahwa membutuhkan tenaga tambahan. ${ }^{9}$ Hanya sebagian kecil puskesmas menggunakan tenaga dari tim NS (4,1\%), karena tidak semua puskesmas yang sudah dilatih PIS-PK memiliki tim NS. Hal tersebut sesuai dengan Permenkes Nomor 16 Tahun 2017 bahwa penugasan khusus tenaga kesehatan dalam mendukung program Nusantara Sehat dilakukan 
dengan menempatkan tenaga kesehatan pada puskesmas dengan kriteria terpencil dan sangat terpencil terutama di Daerah Tertinggal Perbatasan dan Kepulauan Terluar (DTPK). ${ }^{14}$

Selain petugas puskesmas, yang paling banyak melakukan pendataan dan tim NS yang paling sedikit melakukan pendataan, ada juga kader, mahasiswa kesehatan dan mahasiswa non-kesehatan yang melakukan pendataan. Hal ini sesuai dengan penelitian Virdasari, dkk (2018) di Semarang bahwa dalam pelaksanaan kegiatan pendataan keluarga bekerjasama dengan mahasiswa kesehatan dan tenaga survei kesehatan (Gasurkes). ${ }^{13}$ Hal tersebut juga sesuai dengan petunjuk teknis penguatan manajemen puskesmas (2016) bahwa petugas pendataan yang direkrut adalah tenaga kesehatan maupun tenaga non-kesehatan. ${ }^{9}$

Sebaiknya yang melakukan pendataan adalah petugas yang sudah mengikuti pelatihan keluarga sehat, karena tahapan pelaksanaan PIS-PK adalah melalui pelaksanaan pelatihan keluarga sehat dalam mendukung PIS-PK. Demikian juga menurut Laelasari (2017), agar pelaksanaan pendataan sesuai dengan petunjuk dari pusat, puskesmas mensyaratkan SDM yang terlibat adalah petugas yang sudah mengikuti pelatihan. Tenaga lain seperti bidan desa juga dilibatkan dalam kegiatan pendataan, namun tetap didampingi oleh petugas yang sudah dilatih. ${ }^{15}$ Hasil penelitian Salamate, dkk (2014) menyebutkan bahwa pendidikan dan pelatihan merupakan salah satu wadah bagi SDM kesehatan untuk memperoleh keahlian. ${ }^{16}$

\section{Prasarana Puskesmas}

Pendekatan keluarga di puskesmas dapat terlaksana dengan adanya pemenuhan sumber daya puskesmas antara lain SDM, prasarana dan sarana/alat. Menurut Hidayati (2011), sarana/alat merupakan suatu unsur dari suatu organisasi untuk mencapai suatu tujuan. Sarana termasuk dalam salah satu unsur dalam program pelayanan kesehatan yang dibutuhkan untuk mencapai penyelenggaraan program pelayanan kesehatan. Oleh karena itu, agar suatu program menjadi bermutu maka persyaratan ketersediaan sarana prasarana harus terpenuhi. ${ }^{17}$

Dalam melakukan pendataan diperlukan instrumen berupa formulir Prokesga, yang dapat berbentuk cetak ataupun elektronik. Instrumen tersebut merupakan sarana untuk merekam dan menyimpan data anggota keluarga, data kesehatan keluarga, data perilaku individu dan data lingkungan rumah. Selain formulir Prokesga diperlukan juga Paket Informasi Kesehatan Keluarga (Pinkesga) yang berupa flyer untuk diberikan kepada keluarga yang dikunjungi sebagai media komunikasi, informasi dan edukasi (KIE). ${ }^{9}$

Grafik 3 memperlihatkan bahwa 97,8 persen puskesmas menggunakan formulir Prokesga, dan sebanyak 62,3 persen menggunakan Aplikasi Prokesga. Dari Grafik 3 terlihat hampir seluruh puskesmas yang dilatih PIS-PK sudah menggunakan formulir Prokesga dalam pendataan hanya 2,2 persen yang belum, kemungkinan hal ini disebabkan belum semua puskesmas yang sudah dilatih PIS-PK melakukan pendataan. Puskesmas yang menggunakan aplikasi baru 62,3 persen, hal ini kemungkinan disebabkan karena aplikasi membutuhkan sinyal internet yang kuat sedangkan beberapa puskesmas memiliki sinyal internet kurang kuat. Hal tersebut sesuai dengan penelitian Laelasari (2017), yang menunjukkan bahwa terdapat kendala teknis dari aplikasi entri Prokesga, mengingat PISPK merupakan program baru di Kemenkes, sistem yang mendukung kelancaran belum sepenuhnya sempurna dan adanya keterbatasan sinyal internet di daerah sehingga kesulitan pada saat harus mengentri data secara online. ${ }^{15}$ Hasil kajian Aranda Jan et al. (2014) di Afrika, bahwa partisipasi pemerintah melalui kementerian kesehatan merupakan aspek mendasar dalam keberhasilan projek m-Health di Afrika, ketika ada peran dan tanggung jawab yang tumpang tindih antara pengambil keputusan dan pelaksana yang terlibat dalam projek m-Health. Selain itu akses jaringan, internet dan listrik adalah prasyarat aplikasi m-Health untuk dapat berfungsi dengan baik. ${ }^{18}$ Demikian juga dengan hasil Risnakes pada Grafik 4, bahwa belum semua puskesmas yang dilatih PIS-PK memiliki sinyal ponsel $(85,8 \%)$, juga keberadaan sinyal internet, di mana belum semua puskesmas yang dilatih PIS-PK memiliki sinyal internet $(73,2 \%){ }^{8}$

Pada Grafik 6 terlihat bahwa ketersediaan Pinkesga dan ketersediaan alat ukur tekanan darah digital masih belum seratus persen tersedia di 
puskesmas yang sudah dilatih PIS-PK, di mana Pinkesga hanya 58,8 persen dan alat ukur tekanan darah digital baru 71,4 persen. Hal ini kemungkinan karena puskesmas tidak mempunyai dana untuk memperbanyak Pinkesga. Pinkesga adalah paket informasi kesehatan keluarga yang berisi 12 indikator PIS-PK berupa flyer untuk diberikan kepada keluarga yang dikunjungi, sebagai media KIE. Flyer tersebut berisi tentang Keluarga Berencana (KB), Pemeriksaan Kehamilan, Imunisasi, ASI Eksklusif, Penimbangan Balita, Tuberkulosis, Hipertensi, Kesehatan Jiwa, Bahaya Merokok, Sarana Air Bersih, Jamban Sehat, dan Jaminan Kesehatan Nasional. ${ }^{9}$ Menurut Supardi S, dkk (2002) media leaflet adalah alat bantu visual untuk meningkatkan efektivitas pemberian informasi. Leaflet merupakan alat informasi yang fleksibel yang memiliki penampilan yang cukup menarik dalam menyampaikan pesan pada konsumen. ${ }^{19}$ Hasil penelitian Kamil, dkk (2013) menunjukkan bahwa media cetak KIE yang ada dapat memberikan dorongan kepada masyarakat untuk bersikap dan berperilaku lebih baik untuk menjaga kesehatan mereka. Ditemukan juga bahwa setelah membaca media cetak KIE tentang penyakit tuberkulosis (TB), masyarakat berkeinginan dan berusaha untuk lebih giat berobat dan mengikuti semua petunjuk yang ada pada media cetak KIE tersebut. ${ }^{20}$

Alat ukur tekanan darah digital sangat diperlukan untuk mengukur tekanan darah masyarakat, di mana mengukur tekanan darah adalah salah satu yang dilakukan pada saat kunjungan keluarga, karena petugas yang melakukan pendataan tidak semuanya tenaga kesehatan ada juga yang dari non-kesehatan, yang mana tidak mengerti menggunakan alat ukur tekanan darah air raksa. Hasil penelitian Virdasari (2018) menunjukkan bahwa Puskesmas Mijen mengalami keterbatasan prasarana-sarana dalam kegiatan pendataan keluarga seperti tensimeter, komputer, Pinkesga, stiker, dan family folder..$^{13}$ Demikian juga dengan penelitian Laelasari (2017), yang menunjukkan bahwa keterbatasan dana berakibat pada keterbatasan semua komponen yang berkaitan dengan kelancaran kegiatan seperti anggaran sosialisasi, transpor petugas, penggandaan kuesioner, penggandaan Pinkesga, komputer, laptop, dan sinyal..$^{15}$

\section{Kesimpulan}

Hasil penelitian ini menunjukkan bahwa SDM yang mengikuti pelatihan PIS-PK paling banyak adalah bidan dan petugas yang paling banyak melakukan pengumpulan data keluarga sehat adalah petugas puskesmas. Hampir semua puskesmas dalam melakukan pendataan menggunakan formulir Prokesga sebanyak 97,8 persen. Keberadaan sinyal ponsel di puskesmas sebanyak 85,5 persen dan keberadaan sinyal internet sebanyak 73,2 persen. Baru separuh puskesmas memiliki Pinkesga sebanyak 58,5 persen. Hampir semua puskesmas memiliki stetoskop dan alat ukur tekanan darah air raksa dan hanya $71,4 \%$ persen puskesmas memiliki alat ukur tekanan darah digital.

\section{Saran}

Agar terlaksananya PIS-PK maka perlu ada peningkatan prasarana yang menunjang PIS-PK seperti keberadaan sinyal ponsel dan sinyal internet dimana dalam melakukan pendataan diperlukan adanya sinyal handphone dan sinyal internet yang kuat. Selain itu keberadaan Pinkesga perlu ditambah agar pelaksanaan KIE kepada masyarakat berjalan lancar. Diperlukan penambahan alat ukur tekanan darah digital mengingat bahwa pengumpul data tidak selalu dari tenaga kesehatan.

\section{Ucapan Terima kasih}

Ucapan terima kasih kami sampaikan kepada Kepala Badan Litbang Kesehatan dan Ketua Tim Teknis Risnakes 2017 (Dr. dr. Harimat Hendarwan), yang telah memberi ijin penggunaan data penelitian Risnakes 2017. Terima kasih juga kami sampaikan kepada Penanggung Jawab Blok Kesiapan PIS-PK Risnakes 2017 (drg. Hendrianto Trisnowibowo), para Tim Teknis Risnakes 2017 dan semua pihak yang terlibat dalam penelitian Risnakes 2017 yang tidak dapat kami sebutkan satu persatu.

\section{Daftar Rujukan}

1. Kementerian Kesehatan RI. Permenkes No. 39 Tahun 2016 tentang Pedoman Penyelenggaraan Program Indonesia Sehat Dengan Pendekatan Keluarga. 2016.

2. Kementerian Kesehatan RI. Rencana Strategis Kementerian Kesehatan Tahun 2015-2019. 
Jakarta: Kementerian Kesehatan RI; 2015.

3. Kementerian Kesehatan RI. Pedoman Monitoring dan Evaluasi Pelaksanaan Program Indonesia Sehat Dengan Pendekatan Keluarga (PIS-PK). Jakarta; 2017.

4. Kementerian Kesehatan RI. Pedoman Umum Program Indonesia Sehat Dengan Pendekatan Keluarga. Jakarta; 2016.

5. Kementerian Kesehatan RI. Buletin PIS-PK. Jakarta; 2017.

6. Kementerian Kesehatan RI. Permenkes Nomor 75 Tahun 2014. Jakarta: Kementerian Kesehatan RI; 2014.

7. Nur Mochamad. Kemenkes Fokus Alat Penyediaan di Puskesmas. Jawa Pos [Internet]. 2016; Available from: https://www.jawapos. com/humaniora/29/12/2016/kemenkes-fokuspenyediaan-alat-kesehatan-di-puskesmas

8. Kementerian Kesehatan RI. Laporan Riset Tenaga Kesehatan Tahun 2017. Jakarta; 2018.

9. Kementerian Kesehatan RI. Petunjuk Teknis Penguatan Manajemen Puskesmas Melalui Pendekatan Keluarga. Jakarta; 2016.

10. Kementerian Kesehatan RI. Infodatin Situasi Bidan di Indonesia [Internet]. Jakarta; 2012. Available from: http://www.depkes.go.id/ resources/download/pusdatin/infodatin/ infodatin-bidan.pdf

11. Erlandia DR, Gemiharto I. Evaluasi Model Komunikasi Bidan Desa Sebagai Ujung Tombak Upaya Penurunan Angka Kematian Ibu Bersalin Di Kabupaten Sukabumi Provinsi Jawa Barat. J Kaji Komun [Internet]. 2014;2(2):186-99. Available from: http://jurnal.unpad.ac.id/jkk/ article/view/7385/3388

12. Herman MJ, Supardi S, Yuniar Y. Hubungan Ketersediaan Tenaga Kefarmasian Dengan Karakteristik Puskesmas Dan Praktik Kefarmasian Di Puskesmas. Bul Penelit Sist Kesehat [Internet]. 2013;16(1). Available from: http://ejournal.litbang.depkes.go.id/index.php/ hsr/article/view/3150/3123

13. Virdasari E; Arso S P; Fatmasari E Y. Analisis Kegiatan Pendataan Keluarga Program
Indonesia Sehat Dengan Pendekatan Keluarga Di Puskesmas Kota Semarang. J Kesehat Masy [Internet]. 2018;6(5):52-65. Available from: http://ejournal3.undip.ac.id/index.php/jkm

14. Kementerian Kesehatan RI. Permenkes Nomor 16 Tahun 2017. Nomor 16 Tahun 20172017.

15. Laelasari E, Anwar A, Soerachman R. Evaluasi Kesiapan Pelaksanaan Program Indonesia Sehat Dengan Pendekatan Keluarga. J Ekol Kesehat [Internet]. 2017;16(2):57-72. Available from: http://ejournal.litbang.depkes.go.id/index.php/ jek/article/view/7835

16. Salamate GA, Pangemanan AJMRJN. Analisis Perencanaan Sumber Daya Manusia Kesehatan di Dinas Kesehatan Kabupaten Minahasa Tenggara. JIKMU. 2014; Suplemen V(4):62533.

17. Hidayati AN; Wahyono B. Pelayanan Puskesmas Berbasis Manajemen Terpadu Balita Sakit Dengan Kejadian Pneumonia Balita. Kesehat Masy [Internet]. 2011;7(1):35-40. Available from: http;//journal.unnes.ac.id/index.php/ kemas

18. Aranda-jan CB, Mohutsiwa-dibe N, Loukanova S. Systematic review on what works, what does not work and why of implementation of mobile health ( mHealth ) projects in Africa. BMC Public Health [Internet]. 2014;14(188):1471-2458. Available from: https://bmcpublichealth.biomedcentral.com/ articles/10.1186/1471-2458-14-188

19. Supardi S, Sampurno OD, Notosiswoyo M. Pengaruh Metode Ceramah Dan Media Leaflet Terhadap Perilaku Pengobatan Sendiri Yang Sesuai Dengan Aturan. Bull Penelit Kesehat [Internet]. 2002;30(3):128-38. Available from: http://ejournal.litbang.depkes.go.id/index.php/ BPK/article/view/2131/1155

20. Kamil S, Ibnu IF, Rachman WA. Media Cetak Komunikasi , Informasi Dan Edukasi ( KIE ) Dalam Pengobatan Pasien Tuberculosis Multy Drug Resistant ( TB- MDR ) Di Kota Makassar. Repos Univ Hasanudin. 2013;1-15. 